\title{
Effects of glutaraldehyde concentration, pretreatment time, and type of tissue (porcine versus bovine) on postimplantation calcification
}

\author{
Pranava Sinha, MD, ${ }^{\text {a }}$ David Zurakowski, MD, ${ }^{\mathrm{b}}$ T. K. Susheel Kumar, MD, ${ }^{\mathrm{a}}$ Dingchao He, MD, ${ }^{\mathrm{a}}$ \\ Christopher Rossi, MD, ${ }^{\mathrm{c}}$ and Richard A. Jonas, $\mathrm{MD}^{\mathrm{a}}$
}

\begin{abstract}
Objective: Our objective was to evaluate the effects of glutaraldehyde (GA) concentration, time of pretreatment, and type of tissue (porcine vs bovine) on quantitative and qualitative postimplant calcification of tissues.
\end{abstract}

\begin{abstract}
Methods: Freshly obtained porcine and bovine pericardial tissues were each treated with increasing concentrations of GA (controls, $0.3125 \%, 0.625 \%$, and $1.2 \%$ ) for a fixed time ( 15 minutes) or increasing exposure times $(5,10,20$, and 30 minutes) at a fixed concentration of GA $(0.625 \%)$. Pretreated tissues were subcutaneously implanted in 10-week-old Sprague-Dawley rats for 45 days before explantation. Quantitative calcium analysis was performed by flame atomic spectrophotometry. Histologic examination of tissue samples with hematoxylin and eosin and von Kossa staining was performed for cellular and inflammatory response, autolysis, and calcification.
\end{abstract}

\begin{abstract}
Results: Two-way analysis of variance indicated significantly greater calcium levels at $1.2 \%$ compared with each lower concentration for both porcine and bovine samples $(P<.01)$. Significantly lower calcium levels were detected with increased exposure time in porcine samples $(F=6.97 ; P<.001)$; however, no significant differences in calcium levels were observed between different exposure times for bovine samples $(F=1.46$; $P=.23$ ). Histologic evidence of inflammatory response with infiltration with mononuclear cells, fibroblasts, and histiocytes was seen in all grafts; however, it varied from mild to severe without any pattern. There were no differences in degree or pattern of inflammatory response according to GA concentration or time of exposure. Estimation of amount of calcification by histologic examination correlated with the quantitative assay.

Conclusions: Increasing GA concentration leads to greater calcification with a sharp rise in calcium levels above a concentration of $0.625 \%$, in both bovine and porcine pericardial tissues. At a concentration of $0.625 \%$, increasing pretreatment time is inversely related to tissue calcification for porcine pericardium but not for bovine pericardium. Differences in the tissue composition in terms of cellular content and composition of the extracellular matrix could account for the observed findings. (J Thorac Cardiovasc Surg 2012;143:224-7)
\end{abstract}

Glutaraldehyde (GA) fixation of tissues improves handling, provides greater mechanical stability to the tissues, and reduces the risk of aneurysmal dilation, especially for patches in the systemic circulation, but at the cost of increasing susceptibility to calcification and impairment of growth potential. ${ }^{1}$ GA-pretreated autologous or xenogenic tissues of various origins, with or without various anticalcification processes, are used for various indications, for example,

From the Department of Cardiovascular Surgery, ${ }^{\text {a }}$ Children's National Medical Center, Washington, DC; the Department of Anesthesia and Surgery, ${ }^{\mathrm{b}}$ Children's Hospital Boston, Harvard Medical School, Boston, Mass; and the Department of Pathology, ${ }^{\mathrm{c}}$ Children's National Medical Center, Washington, DC.

Disclosures: Authors have nothing to disclose with regard to commercial support.

Read at the 37th Annual Meeting of The Western Thoracic Surgical Association, Colorado Springs, Colorado, June 22-25, 2010.

Received for publication June 27, 2011; revisions received Aug 12, 2011; accepted for publication Sept 8, 2011; available ahead of print Nov 3, 2011.

Address for reprints: Richard A. Jonas, MD, Chief, Cardiac Surgery, Co-Director, Children's National Heart Institute, Cohen Funger Professor of Surgery, Children's National Medical Center, 111 Michigan Ave NW, Washington, DC 20010 (E-mail: rjonas@cnmc.org; lyoung@cnmc.org).

0022-5223/\$0.00

Published by Elsevier Inc. on behalf of The American Association for Thoracic Surgery

doi:10.1016/j.jtcvs.2011.09.043 valve repairs and replacements, conduits, and patches, in surgery for both congenital and acquired cardiac diseases. Long-term outcomes of these procedures, among other factors, are determined by the mechanical properties of the implanted biomaterial and freedom from calcification. Optimal pretreatment times and GA concentrations applicable to clinical practice are not known. It is unclear from previous studies whether mitigation in calcification occurs with prolonged exposure times or higher GA concentrations. $^{2-4}$ Previous studies used extremely long GA exposure times $^{2,4}$ and GA concentrations ${ }^{2,3}$ that are unsafe and impractical for clinical use. This study aims to determine the effect of exposure time and concentration of GA and to determine the optimal conditions for pretreatment of tissues during reconstructive cardiac surgery. It also aims to identify species-specific susceptibility to calcification.

\section{METHODS}

The Institutional Animal Care and Use Committee of Children's National Medical Center approved the study, and all animals were treated in accordance with the "Guide for the Care and Use of Laboratory Animals" (National Institutes of Health publication No. 85-23, revised 1996). Freshly 


\section{Abbreviations and Acronyms \\ ANOVA $=$ analysis of variance \\ GA $=$ glutaraldehyde}

TABLE 1. Glutaraldehyde concentration and calcification in porcine and bovine pericardial tissues

\begin{tabular}{llcc}
\hline Concentration & Group & Mean calcium content & $\mathbf{9 5} \%$ CI \\
\hline Control & Porcine & 1.94 & $1.03-2.85$ \\
& Bovine & 1.56 & $0.65-2.47$ \\
$0.3125 \%$ & Porcine & 2.07 & $1.16-2.98$ \\
& Bovine & 1.06 & $0.12-1.99$ \\
$0.625 \%$ & Porcine & 2.10 & $1.16-3.04$ \\
& Bovine & 1.48 & $0.57-2.39$ \\
$1.2 \% *$ & Porcine & 4.32 & $3.39-5.26$ \\
& Bovine & 4.23 & $3.24-5.23$ \\
\hline
\end{tabular}

All data are expressed as micrograms per milligram of tissue. $C I$, Confidence inter vals. *Significant difference at $1.2 \%$ for both porcine and bovine tissue compared with other concentrations.

oxidizes to a more polar carboxyl moiety and leads to calcification. ${ }^{5}$ Calcification depends on extracellular matrix composition, ${ }^{6,7}$ cellular density, ${ }^{8-11}$ calcium diffusion properties, ${ }^{12}$ and GA penetration into the tissues, ${ }^{13}$ along with other factors like GA concentration, exposure time, and anticalcification process used. Despite intrinsic differences between bovine and porcine tissues, ${ }^{14}$ similar biochemical, kinetic, and morphologic features of mineralization were noted in tissues of different origins in previous reports. The tissues compared in earlier studies were not only from different species (bovine vs porcine) but also differed in their anatomic source (pericardium vs aortic valve cusps). ${ }^{15}$ This study for the first time clearly demonstrates the differences in calcification of bovine and porcine pericardial tissues with GA pretreatment at low concentrations and exposure times.

An increase in calcification with increasing GA exposure times in bovine pericardium is noted, similar to the findings of Liao and associates. ${ }^{4}$ Reduction in porcine pericardial tissue calcification was noted with increasing exposure times. GA penetration in tissues is variable. ${ }^{15,16}$ Incomplete penetration can lead to partial cross-linkage with increased susceptibility to calcification. ${ }^{5}$ Better penetration can be achieved by increasing exposure time, which for thicker tissues with high collagen content (eg, the aortic wall) can take up to 7 days. ${ }^{17} \mathrm{GA}$ penetration in the relatively thinner porcine tissue is probably complete by 30 minutes, leading to complete cross-linkage and lower calcification levels. Similar to earlier observations, ${ }^{5}$ calcification in the bovine tissue was noted in the central layer, supporting incomplete GA penetration in the deeper tissue layers and its role in the calcification process owing to incomplete cross-linkage. Arguably, exposure times in this study were insufficient for complete GA penetration in bovine tissues, and similar reduction in calcification may be noted with longer exposure times. This is supported by lower calcification seen with pretreatment with high concentrations of GA (up to $3 \%$ ) for prolonged periods of time (2-7 days). ${ }^{2,3}$ Additional differences in cellular and extracellular composition between species can lead to difference in susceptibility to calcification.

ing in protein cross-linkage. Any free aldehyde groups on the surface of the implant owing to incomplete crosslinkage or slow release of residual GA after implantation 

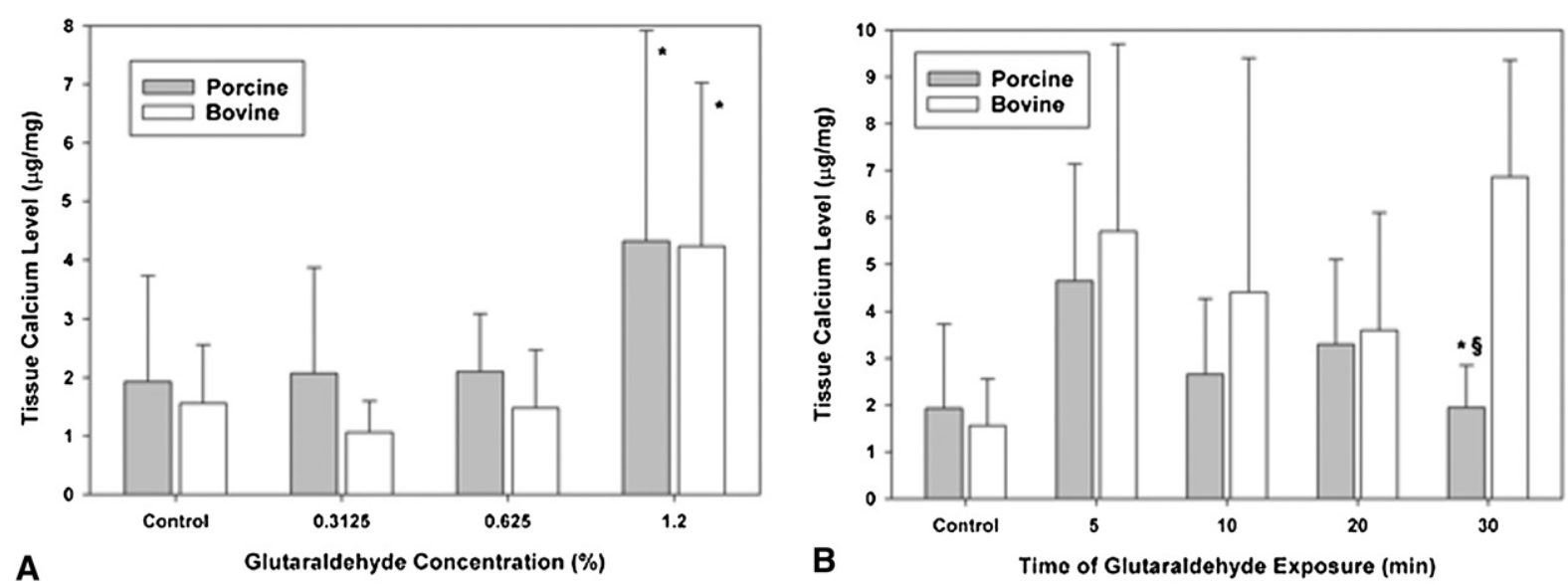

FIGURE 1. A and B, Tissue calcification with glutaraldehyde concentration and exposure time. *Significant difference at $1.2 \%$ compared with other concentrations for both tissues (A). *Significant difference between bovine and porcine tissues (B). §Significant defference between porcine tissue at 30 minutes and porcine tissue at other times (B).

The role of GA pretreatment in imparting tissue resistance to proteinases ${ }^{7}$ is widely know and is supported by the increased autolysis observed with low concentration and exposure times to GA in this study. In vitro studies have shown that increasing concentrations of GA lead to increase in the molecular length of GA polymers without increasing cross-link density, ${ }^{18}$ thus increasing the amount of free aldehyde available for oxidation and mineralization. Higher GA uptake by tissues has been shown to enhance tissue calcification, despite reduction in free lysine and hydroxylysine residues, owing to a similar mechanism. ${ }^{19}$ This explains the linear increase in calcification with increasing concentrations noted in this study. Reduction in calcification attributed to higher concentrations of $\mathrm{GA}^{2,3}$ perhaps was predominantly the result of prolonged exposure times, as is clear from our findings for both porcine and bovine tissues.

We did not assess mechanical properties of tissues in this study. However, on gross examination, bovine pericardium

TABLE 2. Glutaraldehyde exposure times and calcification in porcine and bovine pericardial tissues

\begin{tabular}{llcc}
\hline Exposure time & Group & Mean calcium content & $\mathbf{9 5} \%$ CI \\
\hline Control & Porcine & 1.94 & $1.03-2.85$ \\
$5 \mathrm{~min}$ & Porcine & 4.64 & $2.97-6.30$ \\
$10 \mathrm{~min}$ & Porcine & 2.66 & $0.99-4.33$ \\
$20 \mathrm{~min}$ & Porcine & 3.30 & $1.59-5.02$ \\
$30 \mathrm{~min} *, \dagger$ & Porcine & 1.95 & $0.29-3.62$ \\
Control & Bovine & 1.56 & $0.65-2.47$ \\
$5 \mathrm{~min}$ & Bovine & 5.69 & $3.97-7.41$ \\
$10 \mathrm{~min}$ & Bovine & 4.40 & $2.63-6.17$ \\
$20 \mathrm{~min}$ & Bovine & 3.59 & $1.93-5.27$ \\
$30 \mathrm{~min}$ & Bovine & 6.86 & $5.03-8.69$ \\
\hline $\mathrm{All}$
\end{tabular}

All data are expressed as micrograms per milligram of tissue. $C I$, Confidence intervals. *Significant difference between bovine and porcine tissues. $\dagger$ Significant difference between porcine tissue at 30 minutes and porcine tissue at other times. was noted to be much thicker and stiffer than porcine tissue, both before and after GA treatment. Human pericardium shares its gross properties with porcine pericardium in terms of thickness and post-GA treatment stiffness, and we speculate that it will behave more like porcine pericardium. By demonstrating differences in the tissue of bovine and porcine origin, this exposes the differences between the various bioprosthetic valves in current clinical use. Comparison of various proprietary bioprosthetic valves can be valid only if made for similar tissue sources. ${ }^{20,21}$ Given that current bioprosthetic valves are derived from various origins (eg, bovine pericardium, porcine aortic cusps, equine aortic cusps), a head to head comparison of tissue sources and various proprietary antimineralization processes is much needed.

Calcification is only one of the modes of failure for bioprosthetic heart valves and tissue implants.

Tissues were not decellularized, therefore leaving intact the cellular calcification pathway, ${ }^{8,10,11}$ which may be confounding. Furthermore, this study addresses calcification alone, and further studies to assess mechanical properties of treated tissue are needed to determine the overall optimal pretreatment process. Data regarding anticalcification treatments obtained from subcutaneous implantation studies in small animal models may not hold true in vivo, ${ }^{22}$ although this has been a standard laboratory model for many years. Ideally, these results should be validated by studies with intravascular implantation in large animals.

\section{CONCLUSIONS}

Susceptibility to calcification is species specific. Increasing GA concentration leads to increase in calcification, especially at concentrations greater than $0.625 \%$. Reduction in calcification is noted with increasing exposure time to 30 minutes in porcine pericardial tissue when compared 

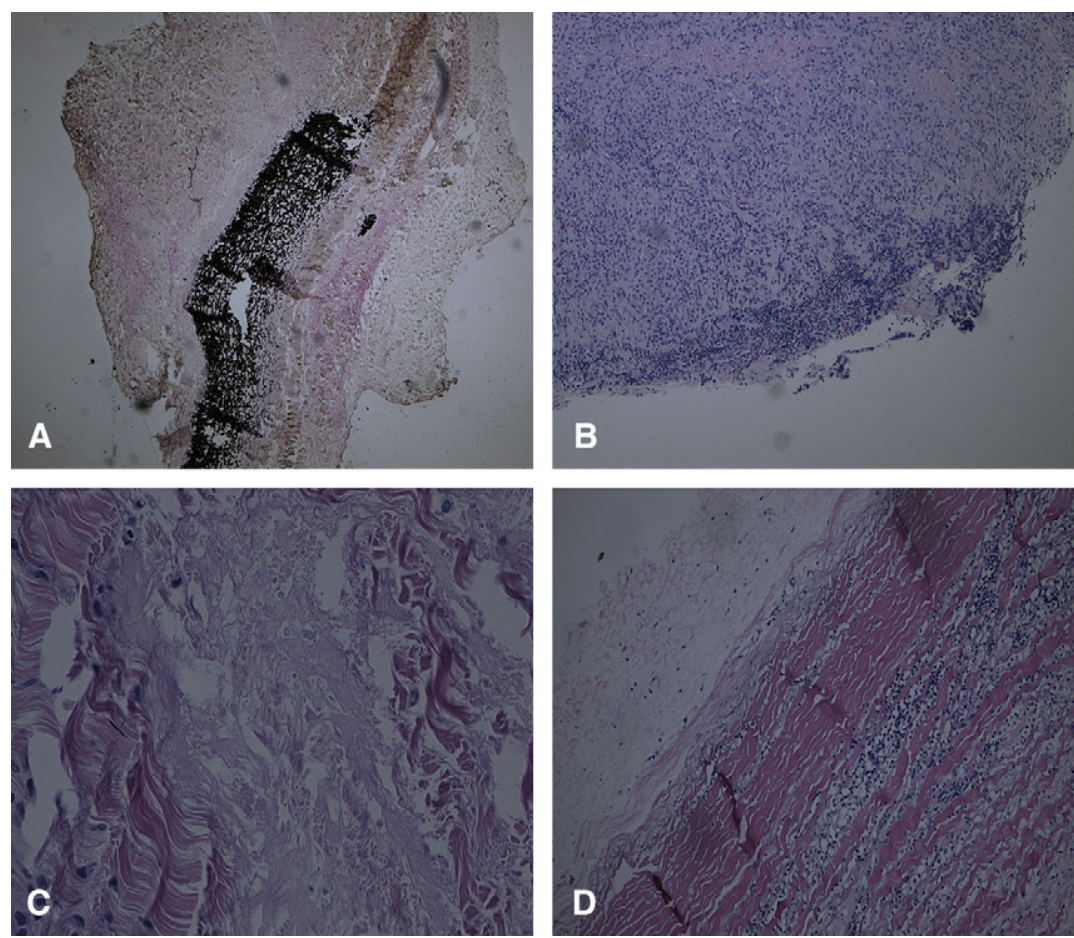

FIGURE 2. Qualitative analysis of tissues by hematoxin \& eosin and Van-Kossa staining. A, Van-Kossa staining showing severe calcification in Bovine pericardium treated with $1.2 \%$ glutaraldehyde. B, Severe inflammatory response seen in bovine pericardium treated with $1.2 \%$ glutaraldehyde. C, Severe autolysis seen in controls. D, Moderate inflammatory response and autolysis seen in bovine pericardium treated for 5 minutes with $0.625 \%$ glutaraldehyde.

with shorter exposure times. Shorter exposure times do not reduce calcification and lead to increased autolysis.

\section{References}

1. Jonas RA. Comprehensive surgical management of congenital heart disease: biomaterials for congenital cardiac surgery. London: Hodder Arnold; 2004. p. 29-44.

2. Zilla P, Weissenstein C, Bracher M, Zhang Y, Koen W, Human P, et al. High glutaraldehyde concentrations reduce rather than increase the calcification of aortic wall tissue. J Heart Valve Dis. 1997;6:502-9.

3. Zilla P, Weissenstein C, Human P, Dower T, von Oppell UO. High glutaraldehyde concentrations mitigate bioprosthetic root calcification in the sheep model. Ann Thorac Surg. 2000;70:2091-5.

4. Liao K, Frater RW, LaPietra A, Ciuffo G, Ilardi CF, Seifter E. Time-dependent effect of glutaraldehyde on the tendency to calcify of both autografts and xenografts. Ann Thorac Surg. 1995;60(2 Suppl):S343-7.

5. Chanda J. Prevention of calcification of heart valve bioprostheses: an experimental study in rat. Ann Thorac Surg. 1995 Aug;60(2 Suppl):S339-42.

6. Bailey MT, Pillarisetti S, Xiao H, Vyavahare NR. Role of elastin in pathologic calcification of xenograft heart valves. J Biomed Mater Res A. 2003;66:93-102.

7. Schoen FJ, Levy RJ. Calcification of tissue heart valve substitutes: progress toward understanding and prevention. Ann Thorac Surg. 2005;79:1072-80.

8. Meuris B, Verbeken E, Flameng W. Prevention of porcine aortic wall calcification by acellularization: necessity for a non-glutaraldehyde-based fixation treatment. J Heart Valve Dis. 2005;14:358-63; discussion 63-4.

9. Meuris B, Ozaki S, Herijgers P, Verbeken E, Flameng W. Influence of species, environmental factors, and tissue cellularity on calcification of porcine aortic wall tissue. Semin Thorac Cardiovasc Surg. 2001;13(4 Suppl. 1):99-105.

10. Kim KM. Cellular mechanism of calcification and its prevention in glutaraldehyde treated vascular tissue. Z Kardiol. 2001;90(Suppl. 3):99-105.

11. Kim KM. Cells, rather than extracellular matrix, nucleate apatite in glutaraldehydetreated vascular tissue. J Biomed Mater Res. 2002 Mar 15;59:639-45.
12. Chen W, Schoen FJ, Levy RJ. Mechanism of efficacy of 2-amino oleic acid for inhibition of calcification of glutaraldehyde-pretreated porcine bioprosthetic heart valves. Circulation. 1994;90:323-9.

13. Chanda J, Kuribayashi R, Abe T. Prevention of calcification in glutaraldehyde-treated porcine aortic and pulmonary valves. Ann Thorac Surg. 1997;64:1063-6.

14. Liao K, Seifter E, Hoffman D, Yellin EL, Frater RW. Bovine pericardium versus porcine aortic valve: comparison of tissue biological properties as prosthetic valves. Artif Organs. 1992;16:361-5.

15. Schoen FJ, Tsao JW, Levy RJ. Calcification of bovine pericardium used in cardiac valve bioprostheses. Implications for the mechanisms of bioprosthetic tissue mineralization. Am J Pathol. 1986;123:134-45.

16. Chanda J. Anticalcification treatment of pericardial prostheses. Biomaterials 1994;15:465-9.

17. Girardot MN, Torrianni M, Dillehay D, Girardot JM. Role of glutaraldehyde in calcification of porcine heart valves: comparing cusp and wall. J Biomed Mater Res. 1995;29:793-801.

18. Cheung DT, Nimni ME. Mechanism of crosslinking of proteins by glutaraldehyde II. Reaction with monomeric and polymeric collagen. Connect Tissue Res. 1982;10:201-16.

19. Golomb G, Schoen FJ, Smith MS, Linden J, Dixon M, Levy RJ. The role of glutaraldehyde-induced cross-links in calcification of bovine pericardium used in cardiac valve bioprostheses. Am J Pathol. 1987;127:122-30.

20. Walther T, Falk V, Diegeler A, Rauch T, Weigl C, Gummert J, et al. Effectiveness of different anticalcification treatments for stentless aortic bioprostheses. Thorac Cardiovasc Surg. 1999;47:23-5.

21. Walther T, Falk V, Autschbach R, Diegeler A, Rauch T, Weigl C, et al. Comparison of different anticalcification treatments for stentless bioprostheses. Ann Thorac Surg. 1998;66(6 Suppl):S249-54.

22. Jones M, Eidbo EE, Hilbert SL, Ferrans VJ, Clark RE. Anticalcification treatments of bioprosthetic heart valves: in vivo studies in sheep. J Card Surg. 1989;4:69-73. 